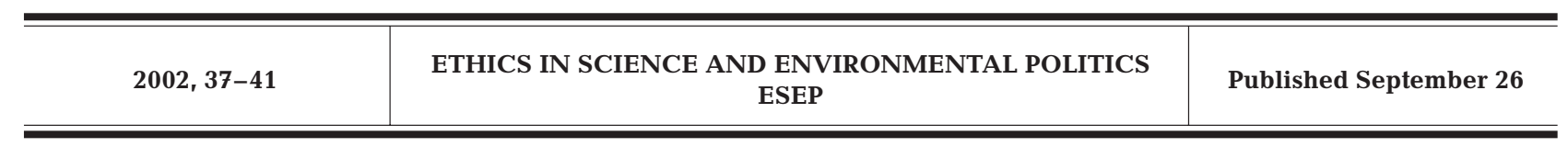

\title{
Stretching the frontiers of precaution
}

\author{
Derek Osborn* \\ 48 Talbot Road, London N6 4QP, United Kingdom
}

\begin{abstract}
The increasing pace and impact of technological change in the world underline the growing need for taking due precautions. In this essay the author reviews a number of cases over the past 2 centuries where new technologies have been introduced too rapidly with too little attention to possible consequences and avoidable damage to health or the environment has been caused. The author goes on to discuss the precautionary approach to new technology, and urges more widespread use of it. He underlines the importance of 4 key points: (1) technology must not be demonised as the enemy - wise use of technology and technological solutions are themselves part of a precautionary approach; (2) a concern for social and environmental justice must be part of a broad precautionary approach - innovations which may potentially benefit one group while putting other groups at risk are very problematic; (3) we must safeguard the public realm and its ability to weigh up proposed innovations and new processes dispassionately - the privatisation of regulation and management of safeguards is very dangerous; (4) innovation and the management of precautionary safeguards are too important to be left to experts or governments alone - there must be sufficient public understanding and support for the introduction of new technologies with all the risks they may involve if public confidence is not to be eroded and greater restrictions imposed. The precautionary approach does not claim to be the answer to all issues concerning the wise use of new technologies. But it does point the way to how we can use public policy frameworks and processes to guide and constrain technological developments in the most appropriate way, and avoid some of the worst possible outcomes. At a time of accelerating technological change and overwhelming human dominance of the natural environment it is vital that we make wise use of this approach.
\end{abstract}

Resale or republication not permitted without written consent of the publisher

\section{THE INCREASING PACE AND IMPACT OF TECHNOLOGICAL CHANGE - THE GROWING NEED FOR TAKING DUE PRECAUTIONS}

Technological change is the master force of our age. Nations and states, political systems and political programmes compete for attention and are critically important to the distribution of powers and wealth amongst groups and individuals, and to the transmission of knowledge and skills. But the fundamental driver is technology with its ever-increasing range of new products and services, shaping the way we live and work, and the pattern of our needs, demands and aspirations.

\footnotetext{
*E-mail: derek_osborn@csi.com

Technology and the human activity that it supports are now so pre-eminent that it is now the dominant force not only in shaping human society, but also in reshaping the natural world around us. There is now virtually no part of the world untouched by human activity and the majority of the world's land is now actively managed to serve human needs and ends. This land management is now itself increasingly influenced by technology, including the use of more and more complex machinery and the application of more and more chemicals and biotechnological products.

To some extent, of course, human history has always been influenced by the technology available at the time. But there are several factors that make the impact of technology even more dominant today, and the risks it presents more acute and problematic. The pace of technological change appears to be ever accel- 
erating, so there are more and more things that may present risks. And because they evolve so quickly and may become so widespread so quickly, the potential for major worldwide impacts is that much greater. The scale of human activity and the power of modern technology are now clearly the major determinants of changes in the world around us, and there remains very little natural buffer to soak up and absorb human activity without noticeable impact.

All these factors mean that it is now more necessary than ever before for us to regard the care of the natural world around us as a central duty of mankind, not only for its own sake, but also because it provides the setting for our own very existence, and because we have it in our power to make the planet substantially less hospitable to ourselves and our descendants, and to damage ourselves or our fellow world citizens in the process. All those who care for the environment of our planet must today take more and more account of the way in which technological development affects the environment, and what can be done to make that impact benign, or at least not actively malign.

In principle our capacity for wise management of the planet has grown almost in parallel with our capacity to do harm if we get it wrong. In the developed world we enjoy a much higher standard of living than in the past. This gives us the scope to pick and choose amongst new developments much more than our ancestors. We are not obliged by economic necessity to chase after every new invention without consideration of consequences. The scale of our economic success gives us the scope and space and resources to act with more care and discretion in managing technological innovation if we choose to do so. The increase in our knowledge and understanding of natural processes and the effect of human actions has also grown exponentially, so that our ability to forecast and to plan how to optimise our impacts is now vastly greater than at any time in history.

Unfortunately having the capacity to act wisely is not the same thing as doing so. As individuals all of us are risk takers to varying degrees, and rebel at too regular a diet of prudence. We admire and celebrate heroic risk-takers in the field of personal endeavour. The occasional heroic failure of the explorer who loses his life in the mountains or at the poles does not put most of us off-it adds spice to our admiration of the endeavours of the heroes.

We transfer much of this cast of thought to the life of business as well. The heroes of the world of capitalism and globalisation are the entrepreneurs, the risk-takers who invent and promulgate new products and processes. They risk much, and in their world too there are many failures. But the regular failure of businesses with all the hardship that this may cause to individuals does not make us lose faith in the concept of business endeavour. Indeed we celebrate the cut and thrust of business life and the constant competition of new ideas and developments as the lifeblood of the economy and the driver of progress.

Of course if we are invited to put up our own money to back a business venture we very quickly move into the camp of the prudential. When we are in that role, we want very scrupulous analysis of the costs of the enterprise, the risks that may surround it, and the chances of it winning through to profitability. We apply a much higher standard of care.

When we come to the environment, most of us as citizens would like to adopt the role of the prudent lender. We share our environment with our neighbours near and far, and many elements of it are not bought or sold. Nevertheless as new technology impacts the environment we are in effect being asked by the developers to put parts of our common environment at risk to enable their developments to take place. In part we may still admire the heroic readiness of the developers to conquer new frontiers and develop new products and processes. But as virtual backers of their enterprise through our commitment of part of our shared environment to support the developers' activities we want to make very sure that the investment of our environment is safe with them. The problem is how to integrate this concern for the environment into the decision-making processes which shape developers' aspirations and plans, and the market responses and regulatory decisions which permit or constrain those developments.

As the pristine elements of the world's environment have shrunk, as the impacts of technology have become ever more profound, and as the quality of our presentday life has enriched we have come over the years to attach more and more importance to this prudential concern. This concern has underlain the progressive development of sets of principles, frameworks of regulation and codes of practice for guiding or constraining technological development so as to minimise damage or risks to the environment, or even to enhance it.

\section{THE PRECAUTIONARY APPROACH AND THE PRECAUTIONARY PRINCIPLE}

Within those frameworks the precautionary principle has a particular relevance to the problem of reducing risks from technological development. There are many analyses and definitions of the precautionary principle. For the purposes of this paper I make use of a simple formulation drawn up recently by the UK Sustainable Development Commission to guide its own work on these issues: 
Adopting a Precautionary Approach. Scientists, innovators and wealth creators have a crucial part to play in creating genuinely sustainable economic progress. But human ingenuity and technological power is now so great that we are capable of causing serious damage to the environment or to peoples' health through unsustainable development that pays insufficient regard to wider impacts. Society needs to ensure that there is full evaluation of potentially damaging activities so as to avoid or minimise risks. Where there are threats of serious or irreversible damage to the environment or human health, the lack of full scientific certainty should not be used as a reason to delay taking cost-effective action to prevent or minimise such damage.

Intelligent foresight and the taking of precautionary action even in the absence of full scientific proof are the essential elements in the precautionary approach. In recent years many techniques have been developed to turn this basic concept into a full-blown systematic methodology for appraising environmental impacts, evaluating risks, appraising costs and benefits, and applying all these techniques to the process of decision taking on developments, on evaluating existing processes and activities, and on setting standards. A very full analysis of the present state of this art, and the way in which it might be developed further is contained in the Royal Commission on Environmental Pollution's Twenty First Report on Setting Environmental Standards (1998).

Even with all this apparatus and agreement in principle on the necessity of precautionary action cases still keep cropping up where precautions are not taken, warning signs are ignored and problems are created and allowed to multiply and become more acute even when warning signs are present.

A recent publication by the European Environment Agency (EEA 2001) under the admonitory title 'Late lessons from early warnings: the precautionary principle 1896-2000' describes a number of famous or infamous examples of the failure to take warning signals into account in due time and the problems that ensued. The cases cited and described in detail include:

(1) Fisheries. The failure to take account in due time of the warning signs pointing to the collapse of fishing stocks in many of the great fisheries around the world.

(2) Asbestos. The dreadful failure to take account over many years of the accumulating evidence of the dangers of asbestos to workers and the public, and the thousands of painful deaths from mesothelioma that are resulting.

(3) CFCs. The slow reaction to the early warnings of hazards from CFCs and the thousands of extra skin cancers which will occur over the next 50 years in consequence.

(4) Antimicrobials and hormones as growth promoters. The long-standing reluctance to take account of possible side effects and the development of resistances to disease.
(5) Mad cow disease. How reassurances undermined precaution.

The report analyses several other historical examples of failure to apply the precautionary principle or to take sufficient note of early warnings of problems ahead. What these examples show is that the precautionary approach and impact assessment are only as good as the people and organisations which apply them, and can only operate within the current political and public context. If the combination of special interest and commercial pressures are felt strongly by government and regulatory bodies, they can all too easily over-ride the precautionary approach. The cost of precautionary action seems high and immediate - the benefits slow and uncertain. Precaution can be derided as timidity and conservatism - a refusal to accept the challenge of the new. Only after the event do the disastrous effects of such miscalculations become clear.

Are these examples mere aberrations within a century in which most technological advances have been benign? Would that it were so. But for all the examples cited in the EEA report others could be added. The failures of judgement and precaution over the century were no mere isolated instances. They were symptomatic of a world that has been impatient with unwelcome warnings, and where special interests exercised too much power in what was done.

Historically many major environmental decisions and policies have been driven more by the emergence of problems or disasters. We have learned more from unhappy experience than from intelligent foresight and precaution. Of course there is some distortion in this observation because the disasters make the history books and remain in the memory while the quiet success stories of successful application of wise precaution to avoid problems are deeply hidden and unmemorable. Nevertheless the number and scale of environmental problems indicate that we are still far from applying precaution enough or strongly enough.

What then can be done to encourage a wiser approach to critical issues, and to ensure a more general application of the precautionary approach in good time? The EEA report draws 12 late lessons from the failures it has analysed (See Appendix 1). They cover some of the same ground as the Royal Commission Report but make some other significant points which could help change the way in which the precautionary approach is operated.

\section{FOUR KEY ELEMENTS OF THE PRECAUTIONARY APPROACH}

Four points in particular seem to me to be crucial in applying the precautionary approach: 
(1) We must beware of making technology the enemy. Technology may not be able to provide all of the fixes which the world will need to escape from the many problems ahead, and we certainly should not rely on technology to avoid all hard decisions on changing lifestyles which may be necessary to achieve a more eco-efficient world. But we shall certainly need all the help that technology can offer, and we ought to be devoting much more resource to encouraging the quest for technological solutions to the various environmental challenges which our environmental foresight reveals to us.

(2) A greater concern for social environmental justice is an essential element of a more robust process. Technological 'advances' which benefit some groups while prejudicing other groups or the environment are very problematic. We should be particularly careful when the other groups in question are separated from us by place or time, and cannot make their presence felt in our decision-taking processes, or when the adverse consequences affect our common environment (which has no voice of its own).

(3) It is essential to reclaim the public realm. The one essential request we make of our governments and policy-makers and decision-takers is that they act impartially in the best interests of all, rather than at the behest of any sectional interest groups. We cannot expect to get reliable and acceptable decisions if research, analysis and the decision-taking process itself are too much influenced by particular sectors.

(4) The application of intelligent foresight is a duty for society as a whole and for individuals within it. Thorough assessment by experts is essential, but we cannot delegate all responsibility for foresight to scientists and experts. Neither governments nor scientists have a monopoly of wisdom in relation to foresightindeed sometimes they can be particularly blinkered, especially if they have become intellectually committed to a particular model of how things work, or have links to interested parties. The views of the public and laypeople with all their prejudices and misconceptions are an essential part of a robust process for decisionmaking. From this follows the needs for open access to information and for active consultation and participation in decision-making.

\section{A THOUGHT EXPERIMENT - APPLYING THE PRECAUTIONARY APPROACH RETROSPECTIVELY TO THE HISTORICAL DEVELOPMENT OF THE COAL INDUSTRY}

In considering the application of these 4 points it may be interesting to attempt a thought experiment by going back to the early years of the Industrial Revolu- tion, to around 1750, and trying to apply the precautionary approach to the one of the key elements of that revolution - the rapid expansion of the coal industry.

With the benefit of hindsight we might conclude that for a long time the progress of the coal industry was driven too much by the sectional interests of the coal owners and managers, and that for a long time not nearly enough attention was paid to the interests of workers in the industry, the communities affected by it, and the impact of the coal industry and the consumption of coal on the environment.

Our social and industrial history is full of the successive efforts to deal with these issues. We remember with pride the campaigns of the reformers to take children out of the mines, to introduce the miners' safety lamp, to introduce smokeless fuels, to secure compensation for coal-related illnesses. But in retrospect one is shocked by how long it took for these campaigns to get going and come to their successes, and how much suffering and damage was caused on the way, the legacies of which remain with us to this day.

Some people might argue that on balance all these social and environmental costs were worthwhile for the sake of the economic growth and amelioration of other conditions of life which industrialisation would ultimately permit. But the thought experiment of applying the precautionary approach retrospectively suggests that an earlier recognition by the public sector of its responsibilities to all parts of society, and a determination to ensure that the coal industry should grow in a way that minimised risks and damage to health and the environment could have produced a happier trajectory for the industry.

\section{APPLICATION OF THE PRECAUTIONARY APPROACH}

We are currently in the midst of global debates about 2 major issues in which precautionary considerations are central - climate change, and the introduction of genetically modified organisms (GMOs). Once again the capacity of the precautionary principle to guide action is in danger of being overborne by other pressures - the world's insatiable demand for energy, and the pressures to increase crop yields. The 2 cases illustrate 2 different but typical situations.

\section{GMOs}

In the GMO case we are at an early stage. The potential for the new technologies to increase yields and to produce health benefits is gradually becoming clearer. But there is still widespread public unease that 
there may be other unintended consequences to the wider environment which have not been fully assessed or guarded against, and a widespread resistance to being rushed into early market dominance by the promoters of these new technologies before proper evaluation has been fully conducted.

The deepest unease is that our governments may not have access to sufficient independent scientific advice to be able to weigh up the risks and benefits impartially enough. It is even feared that some governments may have become seduced by the prospects of economic benefit held out by the promoters of the new technologies to the point where they cannot see clearly the risks and dangers which GMOs may present, or how to weigh them properly in their regulatory decisions. There is a clear need for strengthening the sources of independent scientific advice in this area, and for governments to open up a much wider public debate about the risks and opportunities of the new technologies. This may help to ensure that balanced decisions are taken, with a wider basis of public support, and that close monitoring is maintained so that there can be early warnings of any serious problems and remedial action taken (Nuffield Council on Bioethics 1999).

\section{Climate change}

In the climate change case we have long-established uses of fossil fuels, formerly supposed to be harmless, but now perceived to be having very serious long-term effects for the world in building up greenhouse gases in the atmosphere. The danger here is not that the warnings are not being heard, but that the changes to peoples' ways of life and the technological changes to achieve a shift to a reduced carbon economy are so great that it is difficult to build an effective public, political and business alliance for the necessary changes.

In this case we are, however, blessed with a strong and independent international scientific community which through the work of the Intergovernmental Panel on Climate Change and other independent scientific work has done a great deal to establish a worldwide consensus on the nature of the problem and the dangers that face the world unless action is taken to reduce carbon emissions. The existence of this public science base, and the excellent and inclusive process which has been established internationally for discussing the issues and agreeing on solutions give some grounds for hope that for once it may prove possible to deal with a major global issue in a precautionary way before the worst consequences arise. But there is a great deal still to be done to ensure this benign outcome.

\section{CONCLUSION}

The precautionary approach does not claim to be the answer to all issues concerning the wise use of new technologies. But it does point the way to how we can use public policy frameworks and processes to guide and constrain technological developments in the most appropriate way, and avoid some of the worst possible outcomes. At a time of accelerating technological change and overwhelming human dominance of the natural environment it is vital that we make wise use of this approach.

Appendix 1. Twelve late lessons from early warnings. Conclusions from the EEA's recent publication.

(1) Acknowledge and respond to ignorance, as well as uncertainty and risk, in technology and public policy-making.

(2) Provide adequate long-term environmental and health monitoring and research into early warnings.

(3) Identify and research to reduce blind spots and gasp in scientific knowledge.

(4) Identify and reduce interdisciplinary obstacles to learning (5) Ensure that real world conditions are adequately accounted for in regulatory appraisal.

(6) Systematically scrutinise the claimed justifications and benefits alongside the potential risks.

(7) Evaluate a range of alternative options for meeting needs alongside the option under appraisal, and promote more robust, diverse and adaptable technologies so as to minimise the costs of surprises and maximise the benefits of innovation. (8) Ensure use of 'lay' and local knowledge, as well as relevant specialist expertise in the appraisal.

(9) Take full account of the assumptions and values of different social groups.

(10) Maintain the regulatory independence from interested parties while retaining an inclusive approach to information and opinion gathering.

(11) Identify and reduce institutional obstacles to learning and action.

(12) Avoid 'paralysis by analysis' by acting to reduce potential harm when there are reasonable grounds for concern.

\section{LITERATURE CITED}

EEA (2001) Late lessons from early warnings: the Precautionary Principle 1896-2000 European Environmental Agency, Environmental Issue Report no. 22, Copenhagen

Nuffield Council on Bioethics (1999) Genetically modified crops: the ethical and social issues. Nuffield Council, London

Royal Commission on Environmental Pollution (1998) Setting environmental standards. 21st Report. HMSO, Cm 4053, London 